\title{
Saving Resources in the Construction of Hydroelectric Power Plants
}

\author{
Mikhail Balzannikov \\ Institute of Economics and Management \\ of Construction and Housing and Utili- \\ ties Services \\ Samara State University of Economics \\ Samara, Russia \\ mi.balz@mail.ru
}

\begin{abstract}
The article describes run-of-the-river hydroelectric power plants. The authors specify the importance of performing technical and economic calculations in justifying the large-sized units of the watersupplying channel of a run-of-the-river hydroelectric power plant: turbine pits and suction (discharge) pipes. The study shows that the amount of construction work and the total cost of building a hydroelectric power plant depend on the size of these water supply units. The research objective is to analyze the validity of establishing the main dimensions of the suction pipes for modern technical and economic conditions. The researchers use the discounted income method. The calculations are performed for a hydroelectric power plant with an elbow suction pipe. The analysis of how the operating conditions of a hydroelectric power plant influence the savings of construction resources is carried out. The analysis shows that saving construction resources by reducing the length of the suction pipe is justified if the hydroelectric power plamt is designed to work only at peak power loads. For hydroelectric power plants operating at semi-peak or base power loads, the additional construction costs would be appropriate if leading to the decrease in pressure loss and to the increase in electricity generation.
\end{abstract}

Keywords-hydroelectric power plant, water supply units, saving construction resources, justification of the size of water supply units.

\section{INTRODUCTION}

Hydropower Plants are complex objects for multiple purposes. They are constructed for satisfying needs of various water users: supplying energy for settlement industrial enterprises, ensuring river navigation, melioration, creating reservoirs, protecting territories from flooding, etc. At their construction and operation ecological conditions and limitations should be taken into account. Some of them are considered in [1] and [2].

Hydroelectric power plants play an important role in providing electricity to various consumers during peak periods of the daily power load, since they have very high maneuvering capabilities [3], [4]. At the same time, such power plants imply significant construction costs, especially when erecting run-of-the-river hydroelectric power stations on lowland rivers [5], [6]. Costs are determined by the use of natural resources: soil, sand, crushed stone, stone, as well as expensive parts containing steel (fittings, embedded elements, metal structures) and cement (placing mass concrete in the construction, manufacturing of reinforced concrete elements) [7], [8].

In order to exclude unreasonable expenses related to expensive building materials during the construction of hydroelectric power plants, designers strive to reduce the geometric dimensions of the large-sized parts of the hydroelectric power plant building, which include the main elements of the water supply system: water intake, turbine pit and suction (discharge) pipe (Fig. 1). However, it should be noted that an excessive decrease in the dimensions of these units leads to an increase in the flow velocity and significantly deteriorates the hydraulic conditions of the water flow. These factors cause flow pressure losses and the decrease in electricity output, i.e. the amount of electricity, the most important resource for which the hydroelectric power plants are built, transferred to consumers is decreased [9], [10]. Thus, when determining the size of large-sized units of the power plant water supply, it is necessary to take into account these multidirectional influencing factors and compare possible options from technical and economic perspectives [11], [12].

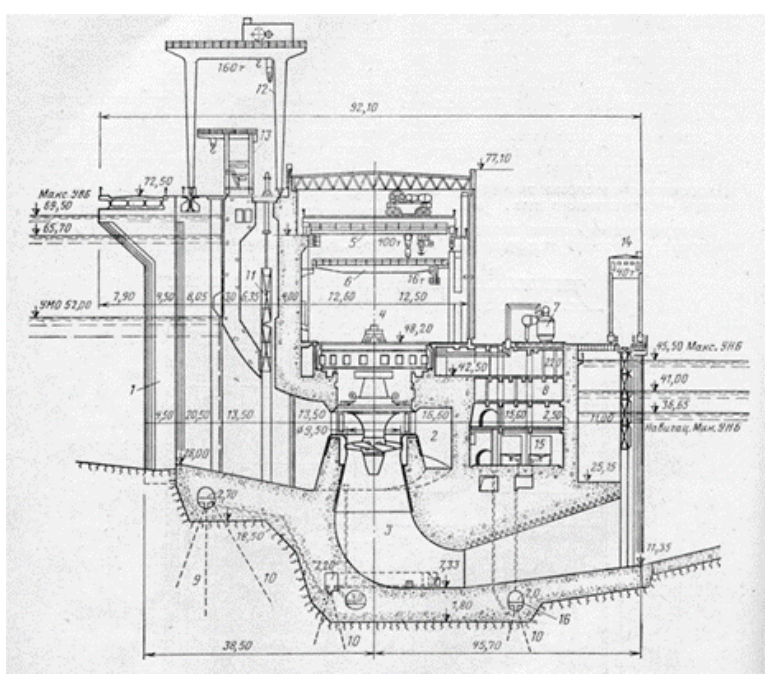

Fig. 1. Building of the run-of-the-river power plant with an elbow pipe: 1 - water intake, 2 - turbine pit, 3 - suction pipe

Print ISSN 1691-5402

Online ISSN 2256-070X

http://dx.doi.org/10.17770/etr2019vol1.4103

(C) 2019 Mikhail Balzannikov.

Published by Rezekne Academy of Technologies. This is an open access article under the Creative Commons Attribution 4.0 International License. 
The objective of the studies is to analyze the validity of the main designated dimensions of one of the most critical large-sized components of the run-of-the-river hydroelectric power plant water supply - suction (discharge) pipes in terms of modern technical and economic conditions.

\section{MATERIALS AND METHODS}

The studies were carried out for a run-of-the-river hydroelectric power plant with parameters close to those of hydroelectric power plants built on the Volga River (Russia) on non-rocky soils. The modular buildings of these hydropower plants are equipped with large-diameter vertical water turbines. Suction pipes of such large hydropower units have elbow type designs (Fig. 1). Compared with axial vertical suction pipes, this form allows for less depth of the foundation of the modular building and less construction work during its erection. The minimum size of the vertical part of the suction pipe is subject to the requirements of the manufacturer of water turbines. These minimum dimensions are approved for the Volga hydroelectric plants [13].

The length of the diffuser (expanding in a vertical plane) part of the suction pipe does not affect the depth of the modular building, but affects the amount of concrete used and the volume of excavation for laying concrete. In order to save building resources (first, concrete), in the course of construction, the suction pipe was also designed as short as possible. Below are the studies of the feasibility of such a solution from the point of view of present day conditions.

The initial parameters of the examined variations of the geometric dimensions of the suction pipe are close to the approved parameters of the largest hydroelectric power plants on the Volga River [13]. Table I lists the main parameters.

In the calculations, we considered the variations of a suction pipe with an increased length toward the downstream by the value of $\Delta \mathrm{L}$. For each option, we counted the increase in the use of construction resources in terms of money $\Delta \mathrm{P}$ according to the formula:

$$
\Delta P=\sum c_{i} W_{i}+\sum s_{i} W_{i}
$$

where $c_{i}$ is the cost of $i$ building resource (concrete, soil), $s_{i}$ is the cost of performing the works for the $i$ resource, $W_{i}$ is $i$ construction resource volume.

TABLE I.

The Main Initial Parameters of the Hydroelectric Power Plant and the Suction Pipe

\begin{tabular}{|c|l|c|}
\hline Number & \multicolumn{1}{|c|}{ Parameter } & Value \\
\hline 1 & $\begin{array}{c}\text { Hydro power plant hydraulic unit capacity, } \\
\text { thousand } \mathrm{kW}\end{array}$ & 120 \\
\hline 2 & Head, $\mathrm{m}$ & 24 \\
\hline 3 & Water turbine diameter, $\mathrm{m}$ & 8.2 \\
\hline 4 & Estimated water consumption, $\mathrm{m}^{3} / \mathrm{s}$ & 560 \\
\hline 5 & $\begin{array}{c}\text { Initial length of the suction pipe (relative to } \\
\text { the turbine diameter) }\end{array}$ & 3.5 \\
\hline
\end{tabular}

However, the increase in the length of the diffuser part of the suction pipe causes an increase in the area of its output section. Thus, the average speed of the water flow in the output section decreases, which causes a decrease in the loss of velocity head in the output section by the value of $\Delta h$ :

$$
\Delta=\left(\begin{array}{ll}
\frac{\alpha V^{2}}{2 g} & \frac{\alpha V_{1}^{2}}{2 g}
\end{array}\right)
$$

where $V$ and $V_{1}$ are the average flow rates of water in the output section of the initial version and the version with an extended diffuser section, respectively, $\alpha$ is the coefficient of uneven velocity of the water flow.

Reducing head loss, in turn, results in additional power $\Delta N$ and additional power generation $\Delta E$, and, consequently, extra income $\Delta D$ from selling additional electricity, respectively, by the values [14]:

$$
\begin{gathered}
\Delta \mathrm{N}=9,81 \eta \mathrm{Q} \Delta \mathrm{h} \\
\Delta \mathrm{E}=\Delta \mathrm{NT}_{\mathrm{N}} \\
\Delta \mathrm{D}=\Delta \mathrm{Eb}
\end{gathered}
$$

where $\eta$ is the efficiency of the hydroelectric unit, $Q$ is water consumption, $T_{N}$ is the relative annual number of hours of use of hydropower capacity, $b$ is the rate per 1 $\mathrm{kWh}$ of electricity.

Obtaining additional income took place for a number of subsequent years $T$ of hydroelectric power plant operation. For adequate comparison of the additional income with additional expenses, the former was changed to match the initial year, taking into account the discount rate:

$$
\Delta D_{d}=\sum_{t=0}^{T} \Delta D_{t}(1+R)^{-t}
$$

where $\Delta D_{t}$ is the value of additional income per year $t, T$ is the considered calculation period, $t$ is the current year,

\begin{tabular}{|c|c|c|}
\hline Number & Parameter & Value \\
\hline 1 & $\begin{array}{l}\text { Increasing the length of the suction } \\
\text { pipe, } m\end{array}$ & from 0 to 24 \\
\hline 2 & $\begin{array}{l}\text { Hours of use of installed capacity per } \\
\text { year, hours }\end{array}$ & $\begin{array}{l}\text { from } 1000 \\
\text { up to } 7000\end{array}$ \\
\hline \multirow[t]{2}{*}{3} & Electricity rate in the first year, rub $/ \mathrm{kWh}$ & from 3.4 to 4.8 \\
\hline & Dynamics of electricity rate, $\%$ per year & from 0 to 10 \\
\hline 4 & $\begin{array}{l}\text { Additional single costs for construction } \\
\text { work, thousand rubles } / \mathrm{m}^{3}\end{array}$ & from 6 to 12 \\
\hline 5 & Discount rate, \% & $\begin{array}{c}\text { from } 0.02 \\
\text { to } 0.08\end{array}$ \\
\hline 6 & Calculation period, years & from 5 to 20 \\
\hline
\end{tabular}
$R$ is the value of the discount rate.

The ranges of variable parameters for the study of the influence of the suction pipe length are given in Table II.

TABLE II.

VARIABLE PARAMETERS 


\section{RESULTS AND DISCUSSION}

Analytical calculations were carried out using computational tools, and the results were presented in graphical form. Fig. 2 shows the calculated dependences of the additional costs of construction resources on increasing length of the suction pipe for different prices of concrete. Studies have shown that the values of the additional costs do not depend on the hydroelectric power plant operating conditions and are determined directly by the $\Delta L$ parameter.

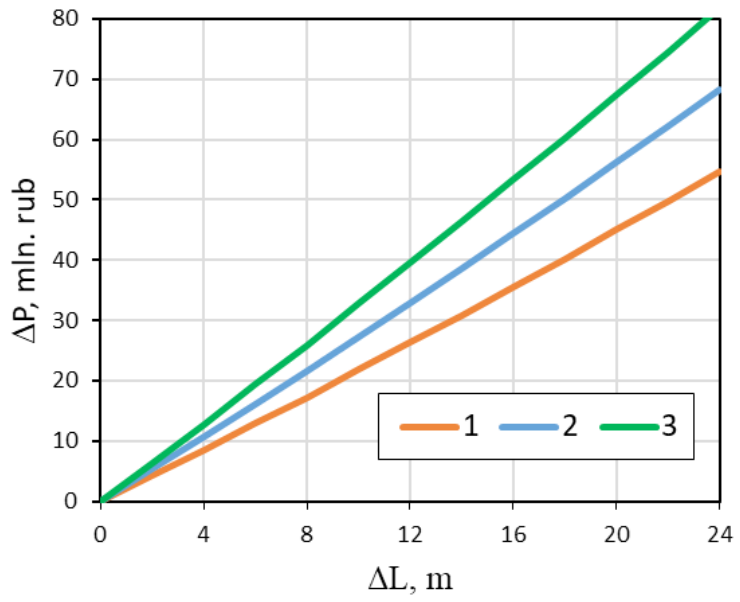

Fig. 2. The growth of additional costs while increasing the length of the suction pipe with the parameters: $1-c_{i}=8000$ rubles, $2-c_{i}=$ 10,000 rubles, $3-c_{i}=12000$ rubles

Fig. 3 shows the results of calculations of the dependencies between the additional revenue of the hydroelectric power plant in current prices and the extension of suction pipe length for different values of $T_{N}$. The graphs show that the $\Delta D$ value significantly depends on the power plant operation mode within the daily load curve - the number of hours of power use. Moreover, the increase of $T_{N}$ leads to an increases of $\Delta D$.

Examples of the dependence of the discounted income and additional construction costs are shown in Fig. 4. The dependences are determined for the period $T=10$ years for different parameters $T_{N}$ with the discount rate $R=0.06$.

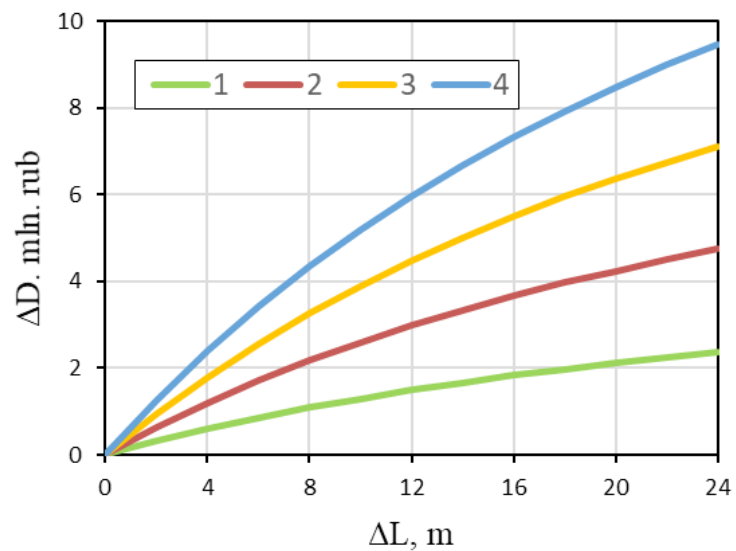

Fig. 3. The growth of additional annual income while increasing the length of the suction pipe with the parameters: $1-T_{N}=1000$ hours, $2-T_{N}=2000$ hours, $3-T_{N}=3000$ hours, $T_{N}=4000$ hours
The overview of the family of the obtained curves shows that for the considered ranges of changes in the operating conditions of the hydropower unit, the initial extension of the suction pipe first causes an increase in economic effect. However, with further increase in the dimensions of the pipe, the effect of the additional electricity generation decreases more intensively, which also causes a decrease in the overall economic effect.

The data obtained indicate that at small number of hours of use of hydroelectric power plant (which is typical of hydroelectric power plants operating at peak times of daily power load curve), the increasing length of the suction pipe has practically no overall economic effect. However, for hydroelectric power plants operating at the semi-peak and base daily power loads, increasing the length of the suction pipe can provide a significant effect. So, at $T_{N}=3000$ hours for the considered parameters of a hydroelectric power plant, an extension of the pipe is economically justified for the whole range $\Delta L$ from 0 to 17.4 $\mathrm{m}$. The maximum effect of 5.5 million rubles can be obtained at $\Delta L=8.0 \mathrm{~m}$. This value can be considered optimal for the length of the suction pipe variable parameter.

The results obtained are important for the correct selection of the main geometrical parameters of the water supply units and can be used in establishing the sizes of the suction pipes in the designs of hydroelectric power plants.

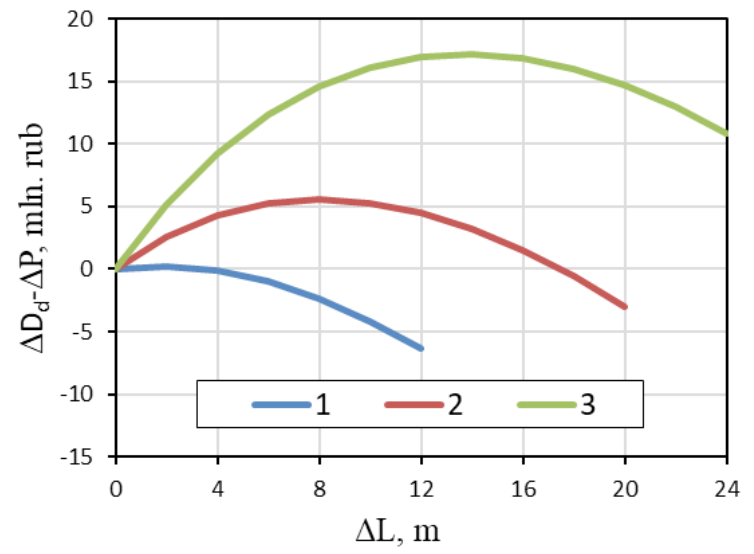

Fig. 4. Difference curve of the discounted income for the period $\mathrm{T}=10$ years and additional construction costs with increasing length of the suction pipe for the parameters: $1-T_{N}=2000$ hours, $2-T_{N}=3000$ hours, $3-T_{N}=4000$ hours

\section{Conclusions}

The main conclusions of the research can be formulated as follows:

1. For hydroelectric run-of-the-river power plants with elbow suction pipes, saving construction resources by reducing the length of the suction pipe is justified if the hydropower station is designed to work only at peak power loads.

2. For hydroelectric power plants operating at semipeak or base power loads, the additional construction costs would be appropriate if leading to the increase in electricity generation. 


\section{REFERENCES}

[1] M. I. Balzannikov and E. G. Vyshkin "Hydroelectric power plants reservoirs and their impact on the environment", Environment. Technology. Resources. Proceedings of the 8-th International Scientific and Practical Conference, Vol. 1, pp. 171-174, 2011.

[2] M. I. Balzannikov, A. A. Mikhasek and V. M. Yurov "Environmental management in joint streams regulation by two hydroelectric complexes", Environment. Technology. Resources, Vol. 1, pp. 23-27, 2017. DOI: http://dx.doi.org/10.17770/etr2017vol1.2638.

[3] Yu. S. Vasiljev and V. V. Yelistratov, Hydroelectric Power Plants. St. Petersburg Polytechnic University. Saint Petersburg, 2011.

[4] F. Svitala and Yu. Galitskova, "Using Hydraulic Power Units with Inclined Axis for Small Hydroelectric Power Plants", Scientific Journal, Vol. 10, pp. 450-456, 2014.

[5] F. Svitala, Yu. Galitskova and S. Evdokimov, "Design Features of Waterworks Facilities and Modular Buildings of the First Hydroelectric Power Plants", Industrial and Civil Engineering, Vol. 12, pp. 87-90, 2014.

[6] M. Balzannikov and S. Piyavskij, "Work Features and Perspective Designs of Suction Pipes of Hydroelectric Power Plants", Vestnik MGSU, Vol. 10, pp. 127-137, 2015.

[7] Yu. Vasiliev and L. Kubyshkin. "On Designing Hydroelectric Power Facilities", Power Technology and Engineering, No. 7, pp. 2-8, 2014.

[8] A. Smyvalov, M. Rodionov and Yu. Galitskova, "Justification of Application of New Types of Fastening of Slopes of Hydraulic Engineering Constructions", MATEC Web of Conferenced, Vol. 117 , pp. 00159, 2017. DOI: 10.1051/matecconf/201711700159.
[9] M. Balzannikov, "Influence of Hydroelectric Power Plants Operation on the choice of the Main Parameters of Suction Pipes", Urban Construction and Architecture, Vol. 4, pp. 86-92, 2015. DOI 10.17673/Vestnik.2015.04.11.

[10] M. Balzannikov, "Research on the Run-of-the-River Hydropower Plant", MATEC Web of Conferences, Vol. 117, pp. 00013 , 2017. DOI: https://doi.org/10.1051/matecconf/201711700013.

[11] M. Balzannikov, "Technical and Economic Viability of Electric Power Plants on The Basis of Renewable Energy Resources Regarding Hierarchical Structure", MATEC Web of Conferences, Vol. 106, pp. 06010, 2017. DOI: https://doi.org/10.1051/matecconf/201710606010.

[12] M. Balzannikov and V. A. Seliverstov, "Characteristics of Substantiation of Water-Intake Parameters at WSPP as Component Parts of the Power Complex", Power Technology and Engineering, Vol. 49, No. 1, pp. 22-26, 2015.

[13] A. Romanov, Zhigulyovsk Hydroelectric Power Station. Operation of Hydraulic Engineering Constructions, Samara, Agni, 2010.

[14] M. Balzannikov, "Feasibility of the Sizes of Water-Conveyance System in Run-Of-The-River Power Plants", MATEC Web of Conferences, Vol. 117, pp. 00012, 2017. DOI: https://doi. org/10.1051/matecconf/201711700012. 